Rev. Fac. Agron. (LUZ). 2021, 38(3): 608-630. Julio-Septiembre.

\title{
Cyclical response of maize populations versus base population and standard genotypes across environments
}

Respuesta cíclica de las poblaciones de maíz frente a la población base y los genotipos estándar en todos los entornos

Resposta cíclica de populações de milho versus população de base e genótipos padrão em ambientes

Mohammad Sajjad ${ }^{1}$, Naqib Ullah Khan ${ }^{1 *}$, Samrin Gul${ }^{2}$, Shahid Ullah Khan ${ }^{3}$, Zarina Bibi ${ }^{4}$, Sardar Ali ${ }^{5}$, Sher Aslam $\mathrm{Khan}^{5}$, Naushad Ali ${ }^{5}$, Iqra Tahir ${ }^{1}$, Amina Habib ${ }^{6}$ and Ijaz Hussain ${ }^{7}$

${ }^{1}$ Department of Plant Breeding and Genetics, University of Agriculture, Peshawar, Pakistan. Email: (MS) muhammadsajjadsro@gmail.com, (D); (NUK) nukmarwat@ yahoo.com, (D). (IT) iqratahir_94@hotmail.com, (D. ${ }^{2}$ Department of Plant Breeding and Genetics, Lasbela University of Agriculture, Water and Marine Sciences (LUAWMS), Uthal, Balochistan, Pakistan. Email: samringulpbg@gmail.com, (D), ${ }^{3}$ Institute of Biotechnology and Genetic Engineering, University of Agriculture, Peshawar, Pakistan. Email: shahidkhanbiotech@gmail.com, (D. ${ }^{4}$ Department of Soil Science, Faculty of Agriculture, Gomal University, Dera Ismail Khan, Pakistan. Email: bibizarina100@ yahoo.com, (D. . ${ }^{5}$ Department of Plant Breeding and Genetics, University of Haripur, Haripur, Pakistan. Email: (SA) sardar_buner@yahoo.com, Đ; (SAK) sheraslamqau@ gmail.com, (D); (NA) naushadturi@gmail.com, (D). ${ }^{6}$ Department of Agricultural Chemistry, University of Agriculture, Peshawar, Pakistan. Email: (AH) aminakhanaup@gmail. com, (D. ${ }^{7}$ Department of Horticulture, University of Haripur, Haripur, Pakistan. Email: ijazhorticulturist@gmail.com, (D).

\section{Abstract}

Recurrent selection is a cyclical breeding procedure in which selection is made generation after generation, with a reunion of selected plants to produce a new population for the next cycle of selection. Maize (Zea mays L.) base population

Received el 17-09-2020 • Accepted 13-11-2020

"Corresponding author. Email: nukmarwat@yahoo.com,nukmarwat@aup.edu.pk 
Rev. Fac. Agron. (LUZ). 2021, 38(3): 608-630. Julio-Septiembre.

Sajjad et al.

ISSN 2477-9407

'PSEV3' was developed by using selfed progeny recurrent selection in spring and summer crop seasons during 2014 to 2016. During Summer 2017, two improved maize populations [PSEV3- $\left(\mathrm{S}_{1}\right)-\mathrm{C}_{1}$ and PSEV3- $\left.\left(\mathrm{S}_{2}\right)-\mathrm{C}_{2}\right]$, original genotype $\left(\mathrm{PSEV} 3-\mathrm{C}_{0}\right.$ ) and three check varieties (two OPV - open-pollinated varieties Azam and Jalal, and HV - hybrid variety - Kiramat) were assessed for silking and yield traits across four environments including two planting dates and two sites i.e., Cereal Crops Research Institute (CCRI), Pirsabak - Nowshera, and University of Agriculture (UAP), Peshawar, Pakistan. Genotypes and planting dates enunciated significant ( $\mathrm{p} \leq 0.01)$ differences for majority of the traits. Maize improved populations $\left(\mathrm{C}_{1}\right.$ and $\left.\mathrm{C}_{2}\right)$ enunciated comparable values with early flowering and least cob height compared to base population and check genotypes. On average, PSEV3- $\left(\mathrm{S}_{2}\right)-\mathrm{C}_{2}$ was foremost and exhibited maximum mean values for yield traits with enhanced grain yield with optimum planting at CCRI, followed by PSEV3-( $\left.\mathrm{S}_{1}\right)-\mathrm{C}_{1}$. Base population - $\mathrm{C}_{0}$ and check genotypes were observed with delayed silking and least grain yield across the environments. Selfed progeny recurrent selection was established as an efficient breeding method in improving maize base populations.

Keywords: selfed progeny recurrent selection, base and improved populations, genotype by environment interaction, earliness and yield traits, Zea mays L.

\section{Resumen}

La selección recurrente es un procedimiento de mejoramiento cíclico en el que la selección se realiza generación tras generación, con una reunión de plantas seleccionadas para producir una nueva población para el siguiente ciclo de selección. La población base de maíz (Zea mays L.) 'PSEV3' se desarrolló utilizando la selección recurrente de progenie autofecundada en las temporadas de cultivo de primavera y verano durante 2014 a 2016. Durante el verano de 2017, dos poblaciones de maíz mejoradas [PSEV3-( $\left.\mathrm{S}_{1}\right)-\mathrm{C}_{1}$ y PSEV3-( $\left.\mathrm{S}_{2}\right)-\mathrm{C}_{2}$ ], el genotipo original (PSEV3- $\mathrm{C}_{0}$ ) y tres variedades de control (dos OPV - variedades de polinización abierta - Azam y Jalal, y HV - variedad híbrida - Kiramat) se evaluaron para determinar los rasgos de rendimiento y sedosidad en cuatro entornos, incluidos dos fechas de siembra y dos sitios, es decir, el Instituto de Investigación de Cultivos de Cereales (CCRI), Pirsabak - Nowshera, y la Universidad de Agricultura (UAP), Peshawar, Pakistán. Los genotipos y fechas de siembra enunciaron diferencias significativas $(p \leq 0,01)$ para la mayoría de los rasgos. Las poblaciones mejoradas de maíz $\left(\mathrm{C}_{1}\right.$ y $\left.\mathrm{C}_{2}\right)$ enunciaron valores comparables con floración temprana y menor altura de mazorca en comparación con la población base y los genotipos de control. En promedio, PSEV3- $\left(\mathrm{S}_{2}\right)-\mathrm{C}_{2}$ fue el primero y exhibió valores medios máximos para los rasgos de rendimiento con rendimiento de grano mejorado con una siembra óptima en CCRI, seguido de PSEV3-( $\left.\mathrm{S}_{1}\right)-\mathrm{C}_{1}$. Población base - Se observaron genotipos de $\mathrm{C}_{0} \mathrm{y}$ control con retraso en la formación de estigmas y menor rendimiento de grano en todos los 
Rev. Fac. Agron. (LUZ). 2021, 38(3): 608-630. Julio-Septiembre.

Sajjad et al.

ISSN 2477-9407

ambientes. La selección recurrente de la progenie autofecundada se estableció como un método de mejoramiento eficaz para mejorar las poblaciones base de maíz.

Palabras clave: selección recurrente de progenie autofecundada, poblaciones base y mejoradas, interacción genotipo por ambiente, rasgos de precocidad y rendimiento, Zea mays L.

\section{Resumo}

A seleção recorrente é um procedimento de melhoramento cíclico no qual a seleção é feita geração após geração, com uma reunião das plantas selecionadas para produzir uma nova população para o próximo ciclo de seleção. A população base de milho (Zea mays L.) 'PSEV3' foi desenvolvida usando a seleção recorrente de progênie autofecundada nas safras de primavera e verão durante 2014 a 2016. Durante o verão de 2017, duas populações de milho melhoraram [PSEV3-( $\left.\mathrm{S}_{1}\right)-\mathrm{C}_{1}$ e PSEV3- $\left(\mathrm{S}_{2}\right)-\mathrm{C}_{2}$ ], genótipo original (PSEV3- $\mathrm{C}_{0}$ ) e três variedades de verificação (duas OPV - variedades de polinização aberta - Azam e Jalal, e HV - variedade híbrida - Kiramat) foram avaliados para características de sedimentação e produção em quatro ambientes, incluindo duas datas de plantio e dois locais, isto é, Cereal Crops Research Institute (CCRI), Pirsabak - Nowshera, e University of Agriculture (UAP), Peshawar, Paquistão. Genótipos e datas de plantio enunciaram diferenças significativas $(\mathrm{p} \leq 0,01)$ para a maioria das características. Populações melhoradas de milho $\left(\mathrm{C}_{1}\right.$ e $\left.\mathrm{C}_{2}\right)$ enunciaram valores comparáveis com floração precoce e menor altura de espiga em comparação com a população de base e genótipos de verificação. Em média, PSEV3- $\left(\mathrm{S}_{2}\right)-\mathrm{C}_{2}$ foi o primeiro e exibiu valores médios máximos para características de rendimento com maior rendimento de grãos com plantio ideal no CCRI, seguido por PSEV3-( $\left.\mathrm{S}_{1}\right)-\mathrm{C}_{1}$. População base - genótipos $\mathrm{C}_{0}$ e testemunha foram observados com silenciamento retardado e menor rendimento de grãos nos ambientes. A seleção recorrente de progênies autogestionadas foi estabelecida como um método de melhoramento eficiente para melhorar as populações de base de milho.

Palavras-chave: seleção recorrente de progênie autofecundada, populações de base e melhoradas, interação genótipo por ambiente, precocidade e características de produção, Zea mays L.

\section{Introduction}

Maize (Zea mays L.) is the primary cereal crop extensively grown in tropical to temperate zones under irrigated and rainfed conditions within $50^{\circ} \mathrm{N}$ to $40^{\circ} \mathrm{S}$ latitude due to its spacious adaptability (Martin et al., 2006; Ali et al., 2020).

\section{Introducción}

El maíz (Zea mays L.) es el principal cultivo de cereal que se cultiva de forma extensiva en zonas tropicales a templadas, bajo condiciones de riego y sequía, entre un rango de latitud de $50^{\circ} \mathrm{N}$ a $40^{\circ} \mathrm{S}$ debido a su amplia 
Being the highest yielding cereal, maize achieved greater importance in combating the food demand of the increasing population worldwide (Khan et al., 2018). In Pakistan, maize grain production was 6.826 million tones from an area of 1,374 million ha having mean yield of 4,968 kg.ha-1 (Pakistan Economic Survey, 2018-2019).

Recurrent selection had been found as an efficient breeding procedure in maintaining genetic variability and improving breeding material. Being a cyclical process, recurrent selection comprising three major steps; family origination, appraisal, and combination of families (Guimaraes et al., 2018; Sheikh et al., 2019). In recurrent selection, improved populations $\mathrm{S}_{1}$ and $\mathrm{S}_{2}$ are believed to be more capable for further improvement (Ayiga-Aluba et al., 2015), and the enviable genes are rapidly organized while adverse factors are purged during early selection in maize (Ali et al., 2018; Sajjad et al., 2020a, b). However, the efficiency of the recurrent selection depends on genetic background, traits heritability, and genes prevalence within maize origional population (Sajjad et al., 2016).

Recurrent selection strengthens the enviable genes for polygenic traits and genetically improve the maize germplasm resources (Sajjad et al., 2020c). Genetic variability might be reduced due to inbreeding during the initial cycles, however, opportunities for selection are not tentative and boost again after selection in maize improved populations (Ali et al., 2019; Sampoux et al., 2020). Past studies reported a significant decrease in earliness and morphological traits such as days to adaptabilidad (Martin et al., 2006; Ali et al., 2020). Siendo el cereal con el más alto rendimiento, el maíz alcanzó una mayor importancia al cubrir la demanda de alimentos de la creciente población mundial (Khan et al., 2018). En Pakistán la producción del grano de maíz fue de 6.826 millones de toneladas por un área de 1.374 millones de hectáreas, teniendo un rendimiento medio de $4.968 \mathrm{~kg} \cdot \mathrm{ha}^{-1}$ (Pakistan Economic Survey, 20182019).

La selección recurrente se ha encontrado como un procedimiento de mejoramiento eficaz para mantener la variabilidad genética y mejorar el material de reproducción. Siendo un proceso cíclico, la selección recurrente comprende tres pasos principales: origen de la familia, valoración y combinación de familias (Guimaraes et al., 2018; Sheikh et al., 2019). En la selección recurrente, se cree que las poblaciones mejoradas $\mathrm{S}_{1}$ y $\mathrm{S}_{2}$ son más capaces de seguir mejorando (Ayiga-Aluba et al., 2015), y los genes deseables son rápidamente organizados, mientras los factores adversos son purgados durante la selección temprana en el maíz (Ali et al., 2018; Sajjad et al., 2020a, b). Sin embargo, la eficiencia de la selección recurrentedependedelosantecedentes genéticos, la heredabilidad de los rasgos y la prevalencia de los genes en la población original de maíz (Sajjad et al., 2016).

La selección recurrente fortalece los genes deseables para los rasgos poligénicos, y genéticamente mejora los recursos del germoplasma del maíz (Sajjad et al., 2020c). La 
male and female flowering, and plant and cob height, while enhancement in yield variables with in maize $\mathrm{S}_{1}$ selection (Kolawole et al., 2017). The $\mathrm{S}_{1}$ recurrent selection exhibited significant positive response with higher grain yield in contrast to selfed and origional genotypes in Zea mays L. (Sohail et al., 2018).

In maize, the recurrent selection is mainly used for population improvement, and to recognize the best performing progenies after each selection cycle. On recurrent selection in maize, extensive studies were conducted and varied estimates were recorded due to different breeding material used, environments, and their interactions (Udo et al., 2017; Chen et al., 2019; Khamkoh et al., 2019). In recurrent selection methods, two aims stay common i.e., to improve the genetic potential of origional population, and sustainable genetic variation in the population to assist in enduring maize breeding program (Guimaraes et al., 2018; Kolawole et al., 2019).

Maize can be grown in a broad array of environments, nonetheless, its production is intensely persuaded by genotypes, environments (sites, crop seasons, and planting dates), and their interaction (GEI) (Ali et al., 2017, 2020; Sajjad et al., 2020a, b). The genotype is an individual's hereditary composition and its performance relies on the ecosystem in the surroundings (Ali et al., 2018; Andorf et al., 2019). Populations may perform differently in diverse environments and may perform well in one environment but not in the other (Ali et al., 2017; Annor et al., 2019). Breeders always expose the newly developed genotypes to variabilidad genética puede reducirse debido a la endogamia durante los ciclos iniciales, sin embargo, las oportunidades para la selección no son provisionales y se potencian de nuevo tras la selección de poblaciones mejoradas de maíz (Ali et al., 2019; Sampoux et al., 2020). Estudios anteriores reportaron una significante disminución en precocidad y rasgos morfológicos tales como los días para la floración masculina y femenina, y longitud de la planta y de la mazorca, mientras que se mejoran las variables de rendimiento en la selección $\mathrm{S} 1$ de maíz (Kolawole et al., 2017). La selección recurrente S1 mostró una respuesta positiva significativa con un mayor rendimiento de grano en contraste con los genotipos autóctonos y originales en Zea mays L. (Sohail et al., 2018).

En el maíz, la selección recurrente es utilizada principalmente para mejorar la población, y reconocer el mejor rendimiento de progenies después de cada ciclo de selección. En la selección recurrente en maíz, se llevaron a cabo estudios exhaustivos y se registraron estimaciones variadas debido a los diferentes materiales de reproducción utilizados, los ambientes y sus interacciones (Udo et al., 2017; Chen et al., 2019; Khamkoh et al., 2019). En los métodos de selección recurrente, dos objetivos siguen siendo comunes: mejorar el potencial genético de la población original, y la variación genética sostenible en la población para ayudar en el programa de reproducción de maíz perdurable (Guimaraes et al., 2018; Kolawole et al., 2019). 
an array of sites and crop seasons to determine the influence of environment on their recital. The genotype with less magnification by the existing climatic conditions is considered most desirable (Annor et al., 2019).

Determination of a suitable site and planting date is very crucial for achieving the best response and high yield in maize (Ali et al., 2020). Optimum and delayed sowing is one of the key ecological aspect which cause marvellous impressions on maize crop and its production. Maize with optimum planting can ensures greater growth which lead to enhanced grain yield (Sajjad et al., 2020a, d). The second imperative feature is the maize genotype, and a significant improvement in grain yield can be expected if it is tied with optimum environmental conditions.

Genotypes interaction with environmental factors (GEI) i.e., sites, seasons, optimum and delayed sowing, and biotic and abiotic stresses are enormous challenges for the plant breeders, and these features are normally used as environments. Therefore, it is earnestly needed that how to shape the genotype with optimum environmental conditions to acquire the highest grain yield. Due to changed climatic conditions, it is direly needed to assess and revise the production technologies as to get the net maximum return from the crop. Consequently, this research was planned with the objective to evaluate the competency of two improved maize populations "PSEV3- $\left(\mathrm{S}_{1}\right)-\mathrm{C}_{1}$ and PSEV3- $\left(\mathrm{S}_{2}\right)-\mathrm{C}_{2}$ " in relationship with origional population $\left(\mathrm{C}_{0}\right)$ and three check genotypes (OPV
El maíz puede ser cultivado en una amplia gama de entornos, sin embargo, su producción está intensamente influenciada por genotipos y ambientes (lugares, temporadas de cultivo y fechas de siembra), y su interacción (GEI) (Ali et al., 2017, 2020; Sajjad et al., 2020a, b). El genotipo es la composición hereditaria de un individuo y su rendimiento depende del ecosistema del entorno (Ali et al., 2018; Andorf et al., 2019). Las poblaciones pueden tener un rendimiento diferente en diversos ambientes, pueden tener un buen rendimiento en un entorno, pero no en otro (Ali et al., 2017; Annor et al., 2019). Los reproductores siempre exponen los genotipos recién desarrollados a una serie de lugares y temporadas de cultivo para determinar la influencia del entorno en su rendimiento. El genotipo con menos alteraciones por las condiciones climáticas existentes se considera más deseable (Annor et al., 2019).

La determinación de un lugar y una fecha de siembra adecuada es crucial para alcanzar la mejor respuesta y un alto rendimiento en el maíz (Ali et al., 2020). Una siembra óptima y tardía es un aspecto ecológico clave, lo cual es determinante en el cultivo de maíz y su producción. El maíz con una siembra optima puede garantizar un mayor crecimiento, lo cual conduce a mejorar el rendimiento del grano (Sajjad et al., 2020a, d). La segunda característica imprescindible es el genotipo del maíz, y se puede esperar una mejora significativa del rendimiento del grano si va unido a unas condiciones ambientales óptimas. 
Rev. Fac. Agron. (LUZ). 2021, 38(3): 608-630. Julio-Septiembre.

Sajjad et al.

ISSN 2477-9407

- Azam and Jalal, and HV - Kiramat) under different environments (sites and planting dates).

\section{Materials and methods}

\section{Development of breeding material}

Maize base population used in study was 'PSEV3' (a cross amid the local maize variety Azam and a single cross white hybrid CHSW - developed by International Maize and Wheat Improvement Center (CIMMYT), Mexico. Two improved maize populations "PSEV3 $\left(\mathrm{S}_{1}\right)-\mathrm{C}_{1}$ and PSEV3 $\left(\mathrm{S}_{2}\right)$ - $\mathrm{C}_{2}$ ” were developed from the origional population (PSEV3) using two cycles of selfed progeny recurrent selection $\left(\mathrm{S}_{1}\right.$ and $\mathrm{S}_{2}$ lines) in five spring and summer crop seasons during 2014 to 2016 at CCRI, Pirsabak - Nowshera, Pakistan (table 1).
La interacción de genotipos con los factores ambientales (GEI) i.e., lugares, temporadas, siembra óptima y tardía, y el estrés biótico y abiótico son grandes retos para los reproductores de plantas, y estas características son normalmente utilizadas como entornos. Por lo tanto, se necesita encarecidamente cómo formar el genotipo con las condiciones ambientales óptimas para adquirir el mayor rendimiento de grano. Debido a los cambios de las condiciones climáticas, es necesario evaluar $\mathrm{y}$ revisar las tecnologías de producción para obtener el máximo rendimiento neto del cultivo. Por consiguiente, esta investigación se planteó el objetivo de evaluar la competencia entre dos poblaciones mejoradas de maíz «PSEV3-( $\left.\mathrm{S}_{1}\right)-\mathrm{C}_{1}$ y PSEV3- $\left(\mathrm{S}_{2}\right)-\mathrm{C}_{2}$ " en relación con la población original $\left(\mathrm{C}_{0}\right)$ y tres genotipos control (OPV:

Table 1. Cyclical populations and check genotypes evaluated at CCRI and UAP.

Cuadro 1. Poblaciones cíclicas y genotipos control evaluados en el CCRI y UAP.

\begin{tabular}{|c|c|c|c|c|}
\hline Genotypes & Type & Plant height & Maturity & Pedigree \\
\hline PSEV3- $\mathrm{C}_{0}$ & $\mathrm{OPP}$ & Medium & Medium & Cross amid Azam and CHSW, CIMMYT \\
\hline PSEV3-( $\left.\mathrm{S}_{1}\right)-\mathrm{C}_{1}$ & OPP & Medium & Medium & Obtained by recombination of $\mathrm{S}_{1}$ reliable lines \\
\hline PSEV3-( $\left.\mathrm{S}_{1}\right)-\mathrm{C}_{2}$ & OPP & Medium & Medium & Obtained by recombination of $S_{2}$ specific lines \\
\hline Azam & OPV & Medium & Medium & Obtained by crossing Akbar with Vikram \\
\hline Jalal & OPV & Tall & Medium & Obtained by crossing Azam with CHSW \\
\hline Kiramat & HV & Medium & Medium & Obtained by crossing FRHW-20-4 with FRHW-22( $\left.\mathrm{F}_{2}\right)-5$ \\
\hline
\end{tabular}

OPP: Open-pollinated population, OPV: Open-pollinated variety, HV: Hybrid variety, Short: 90-130 cm, Medium: $131-170 \mathrm{~cm}$, Tall: $171-210 \mathrm{~cm}$.

OPP: Población de polinización abierta, OPV: Variedad de polinización abierta, HV: Variedad híbrida, Corta: 90-130 cm, Media: 131-170 cm, Alta: $171-210 \mathrm{~cm}$. 
Rev. Fac. Agron. (LUZ). 2021, 38(3): 608-630. Julio-Septiembre.

Sajjad et al.

ISSN 2477-9407

\section{Sites, and experimental procedure}

During summer crop season 2017, newly developed improved populations "PSEV3-( $\left.\mathrm{S}_{1}\right)-\mathrm{C}_{1}$ and PSEV3-( $\left.\mathrm{S}_{2}\right)-\mathrm{C}_{2}$ " were appraised in comparison with origional population $\left(\mathrm{PSEV} 3-\mathrm{C}_{0}\right)$, and three check cultivars (two OPV Azam and Jalal, and HV - Kiramat) with optimum (July 05, 2017) and delayed (July 25, 2017) plantings at two sites i.e., a) CCRI, Pirsabak Nowshera, Pakistan (positioned amid $32^{\circ} \mathrm{N}$ and $72^{\circ} \mathrm{E}$ latitude and longitude, respectively with $288 \mathrm{~m}$ altitude), and b) UAP, Peshawar, Pakistan (located amid $34^{\circ} \mathrm{N}$ and $71^{\circ} \mathrm{E}$ latitude and longitude, respectively with $350 \mathrm{~m}$ altitude). All the maize genotypes were having white flint shape seeds which developed at CCRI, Pirsabak Nowshera, Pakistan. At CCRI, the soil was moderately calcareous and sandy loam with $7.7 \mathrm{pH}, 0.34 \%$ organic matter, $0.034 \%$ nitrogen, $0.0029 \%$ $\mathrm{P}_{2} \mathrm{O}_{5}, 0.051 \% \mathrm{~K}_{2} \mathrm{O}$. However, at UAP the soil was alkaline in nature and silt clay loam with $7.8 \mathrm{pH}, 0.81 \%$ organic matter, $0.063 \%$ nitrogen, $7.18 \mathrm{mg} \cdot \mathrm{kg}^{-1}$ $\mathrm{P}_{2} \mathrm{O}_{5}$, and $112 \mathrm{ppm} \mathrm{K}_{2} \mathrm{O}$. Temperature mean data during the months of the trials at both experimental sites is presented in figure 1.

At each site, the split-plot design was used for the experimental layout with three replications. Planting dates were treated as main-plots whereas maize genotypes were considered as sub plots at both sites. Each sub plot comprising four rows with five meters length, and 0.75 and $0.25 \mathrm{~m}$ rows and plants spacing, respectively.
Azam y Jalal, y HV: Kiramat) bajo diferentes ambientes (lugares y fechas de siembra).

\section{Materiales y métodos}

\section{Desarrollo del material de} reproducción

La población base de maíz utilizada en este estudio fue 'PSEV3', un cruce entre la variedad local de maíz Azam y un híbrido blanco CHSW, desarrollado por el Centro Internacional de Mejoramiento de Maíz y Trigo (CIMMYT), México. Dos poblaciones mejoradas de maíz «PSEV3 $\left(\mathrm{S}_{1}\right)-\mathrm{C}_{1}$ y PSEV3 $\left(\mathrm{S}_{2}\right)-\mathrm{C}_{2}$ ", los cuales fueron desarrollados a partir de la población original (PSEV3) utilizando dos ciclos de selección recurrente de progenie autofecundada (líneas de $\mathrm{S}_{1}$ y $\mathrm{S}_{2}$ ) en cinco temporadas de cultivo de primavera y verano durante el 2014 al 2016 en CCRI, Pirsabak - Nowshera, Pakistán (cuadro 1).

\section{Localidades y procedimiento} experimental

Durante la temporada de cultivos de verano del 2017, las poblaciones mejoradas "PSEV3- $\left(\mathrm{S}_{1}\right)-\mathrm{C}_{1} \quad \mathrm{y}$ PSEV3- $\left(\mathrm{S}_{2}\right)-\mathrm{C}_{2}$ ” fueron valoradas en comparación con la población original (PSEV3- $\left.\mathrm{C}_{0}\right)$, y tres cultivares de control (Dos OPV: Azam y Jalal y HV: Kiramat) con siembras óptimas (Julio 05, 2017) y tardías (Julio 25, 2017) en dos lugares: a) CCRI, Pirsabak - Nowshera, Pakistán (posicionada entre $32^{\circ} \mathrm{N}$ y $72^{\circ} \mathrm{E}$ de latitud y longitud, respectivamente con $288 \mathrm{~m}$ de altitud), y b) UAP, Peshawar, Pakistán (Localizada entre $34^{\circ} \mathrm{N}$ y $71^{\circ} \mathrm{E}$ de latitud y longitud, respectivamente 
Rev. Fac. Agron. (LUZ). 2021, 38(3): 608-630. Julio-Septiembre.

Sajjad et al.

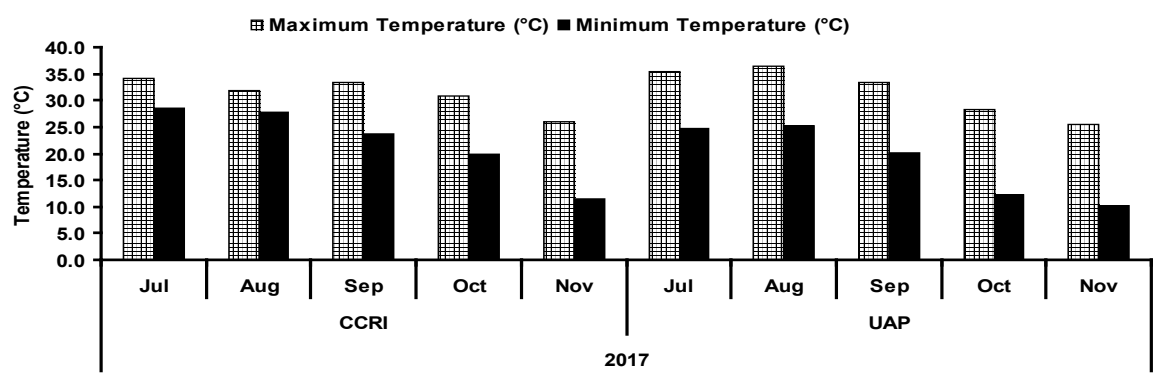

Figure 1. Temperature mean data for summer crop season during 2017 at CCRI and UAP.

Figura 1. Datos de la temperatura media para la temporada de cultivo de verano durante el 2017 en el CCRI y UAP.

\section{Crop husbandry}

The recommended doses of NPK (200:90:90 kg.ha-1) fertilizers were used in the well prepared soil. Nitrogen $(\mathrm{N})$ with half dose, while phosphorus and potash with full doses were utilized in form of urea, single super phosphate and sulphate of potash, respectively during preparation of land and before sowing. The remaining half $\mathrm{N}$ was applied to the crop after four weeks of germination. Primextra Gold (720 $\mathrm{SC}$, at the rate of $1.5 \mathrm{~L} \mathrm{ha}^{-1}$ ) was used as pre-emergence for the weeds control. Hand weeding and earthing up operations were also carried out to keep loose the soil and control the leftover weed flora. Confidor-WP-60 (200 SL, at the rate of $50 \mathrm{~g} .10 \mathrm{~kg}^{-1}$ maize seed) was used as seed treatment for the control of maize borer (Chilo partellus). Furadon $3 \%$ (Carbofuran, at the rate of $20 \mathrm{~kg} \cdot \mathrm{ha}^{-1}$ ) granules were used in the whirls of maize plants after 30 days of emergence. Irrigations were carried out with the appropriate period. All the genotypes con $350 \mathrm{~m}$ de altitud). Todos los genotipos de maíz presentaron semillas con forma de sílex blanco que se desarrollaron en el CCRI, Pirsabak - Nowshera, Pakistán. En el CCRI, el suelo era moderadamente calcáreo y arenoso con un $\mathrm{pH}$ de 7,7 , $0,34 \%$ de materia orgánica, $0,034 \%$ de nitrógeno, 0,0029\% de $\mathrm{P}_{2} \mathrm{O}_{5}, 0,051$ $\%$ de $\mathrm{K}_{2} \mathrm{O}$. Sin embargo, en la UAP el suelo era de naturaleza alcalina y franco arcilloso-limoso con 7,8 de $\mathrm{pH}, 0,81 \%$ de materia orgánica, 0,063\% de nitrógeno, 7,18 mg.kg-1 de $\mathrm{P}_{2} \mathrm{O}_{5}$ y 112 ppm de $\mathrm{K}_{2} \mathrm{O}$. Los datos medios de temperatura durante los meses de los ensayos en ambos sitios experimentales se presentan en la figura 1.

En cada lugar, el diseño de parcelas divididas fue utilizado como diseño experimental con tres repeticiones. Las fechas de siembra fueron tratadas como parcelas principales, mientras que los genotipos de maíz se consideraron como subparcelas en ambos lugares. Cada subparcela 
Rev. Fac. Agron. (LUZ). 2021, 38(3): 608-630. Julio-Septiembre.

Sajjad et al.

ISSN 2477-9407

were uniformly considered at both planting dates and sites.

\section{Data compilation and analysis}

Data for all the parameters were documented on single plant basis in each plot and replication for days to silking, cob height, cobs per plant (prolificacy) and cob length. Grain yield at $15 \%$ moisture level of the grains, was approximated as follows.

Grain yield $\left(\mathrm{kg} \cdot \mathrm{ha}^{-1}\right)=(100-\mathrm{MC}) \times \mathrm{xEW} \times$ Shelling Coefficient $\mathrm{x}$ 10,000 (100-15)xPlot area

Whereas; $\mathrm{MC}=$ Moisture percentage in the grains, FEW $=$ Fresh ear weight $(\mathrm{kg})$ at the time of harvest, Shelling coefficient $=0.80$

All the recorded data regarding evaluation of improved populations - $\mathrm{C}_{1}$ and $\mathrm{C}_{2}$, base population - $\mathrm{C}_{0}$ and check genotypes across environments were subjected to analysis of variance opportune for genotype $\mathrm{x}$ environment interactions (Gomez and Gomez, 1984) using Mstat-C computer program (Bricker, 1991). Means were further dissevered by using $\mathrm{LSD}_{0.05}$.

\section{Results and discussion}

Pooled analysis of variance across six maize populations, two sites and planting dates was conducted for flowering and yield traits (table 2). Sites revealed significant variations for cob height, while nonsignificant for all other traits. Planting dates exhibited highly significant variations for time to silking, while significant for cob height and grain yield. Genotypes enunciated highly significant differences for days to silking and cob length, while constaba de cuatro hileras de cinco metros de longitud y con un espacio entre hileras y plantas de 0,75 y 0,25 $\mathrm{m}$, respectivamente.

\section{Manejo de los cultivos}

Las dosis recomendadas de fertilizantes NPK (200:90:90 $\mathrm{kg} \cdot \mathrm{ha}^{-1}$ ) fueron utilizadas en suelos preparados. Una media dosis de Nitrógeno $(\mathrm{N})$, y una dosis completa de fosforo con potasio se utilizaron en forma de urea, superfosfato simple y sulfato de potasio, respectivamente durante la preparación del terreno y antes de la siembra. La mitad restante de $\mathrm{N}$ se aplicó al cultivo después de cuatro semanas de germinación. Primextra Gold (720 SC, a razón de 1,5 L.ha ${ }^{-1}$ ) fue utilizado como pre-emergencia para el control de malezas. También se llevaron a cabo operaciones de deshierbe manual y de puesta a tierra para mantener el suelo suelto y controlar la flora de malezas sobrantes. Se utilizó Confidor-WP-60 (200 SL, a razón de 50 g.10 $\mathrm{kg}^{-1}$ de semilla de maíz) como tratamiento de semillas para el control del barrenador del maíz (Chilo partellus). Se utilizó Furadon $3 \%$ (Carbofuran, a razón de $20 \mathrm{~kg} \cdot \mathrm{ha}^{-1}$ ) en gránulos en los remolinos de las plantas de maíz después de 30 días de emergencia. Los riegos se realizaron con el período adecuado. Todos los genotipos se consideraron uniformemente en ambas fechas de siembra y lugares.

\section{Recopilación y análisis de datos}

Los datos para todos los parámetros fueron documentados en base a una sola planta, en cada parcela y por repetición: días hasta el ensilado, 
significant for cob height and grain yield. Genotypes revealed greater genetic variability across the sites and planting dates, which can be utilized for identification and improving the maize cyclical populations. Significant variations were recorded among the selected maize $S_{1}$ populations for cob length, cobs per plant, grain rows per cob, thousand kernels weight and grain yield (Sohail et al., 2018; Sheikh et al., 2019). Genotype x environment relationships revealed significant variations for flowering and yield variables which authenticated that maize populations could not sustain uniform phenotypic behaviour over diverse environments (Sajjad et al., 2020a, b). Genotype-by-site interactions revealed significant $(p \leq 0.05)$ differences for cob length while non-significant for other traits. However, site by planting date, genotype by planting date, and genotype $x$ site $x$ planting date revealed non-significant differences for all the traits. Past studies revealed that $\mathrm{G} x$ $\mathrm{E}$ interactions were nonsignificant for earliness traits, plant and cob height, cob traits, and 1000-grain weight in maize (Annor et al., 2019).

\section{Days to silking}

For sites, maize populations consumed least days to silking at UAP (81.81 days) as compared to CCRI (83.14 days) which might be due to high temperature at UAP resulting in stress conditions and early flowering (table 3 and figure 1). In planting times, genotypes with delayed planting exhibited lesser days to silking (76.81 days) than optimum planting (88.14 days). On average, the altura de la mazorca, mazorcas por planta (prolificidad) y la longitud de la planta. El rendimiento de los granos, con un nivel de humedad del $15 \%$, se aproximó de la siguiente manera:

Grain yield $\left(\mathrm{kg} \cdot \mathrm{ha}^{-1}\right)=(100-\mathrm{MC}) \times \mathrm{xFEW} \times \mathrm{Shelling}$ Coefficient $\mathrm{x} 10.000$ $(100-15) x P l o t$ area

Siendo $\mathrm{MC}=$ Porcentaje de humedad en los granos, FEW = Peso fresco de la mazorca $(\mathrm{kg})$ en el momento de la cosecha, Coeficiente de desgrane $=0,80$

Todos los datos registrados con respecto a la evaluación de poblaciones mejoradas - $\mathrm{C}_{1}$ y $\mathrm{C}_{2}$, población base- genotipos $\mathrm{C}_{0} \mathrm{y}$ de control entre ambientes se sometieron a un análisis de varianza oportuno para las interacciones genotipo $\mathrm{x}$ ambiente (Gómez y Gómez, 1984) utilizando el programa informático Mstat-C (Bricker, 1991). Las medias se separaron utilizando $\operatorname{LSD}_{0,05}$.

\section{Resultados y discusión}

El análisis de varianza combinado entre seis poblaciones de maíz, dos lugares y fechas de siembra para los rasgos de floración y rendimiento se muestra en el cuadro 2. Los lugares revelaron variaciones significativas para la altura de la mazorca, mientras que no se mostraron significativas para todos los demás rasgos. Las fechas de siembra mostraron variaciones altamente significativas para el tiempo hasta el ensilado, mientras que no fueron significativas para la altura de la mazorca y el rendimiento del grano. Los genotipos determinaron 
Rev. Fac. Agron. (LUZ). 2021, 38(3): 608-630. Julio-Septiembre.

Sajjad et al.

ISSN 2477-9407

belated planting took minimum days to silking (75.67 and 77.94 days) than optimum planting (87.94 and 88.33 days) with a decline of 11.33 days $(12.85 \%)$. For sites and planting date interactions $(\mathrm{L} \times \mathrm{P})$, time to silking varied from 75.67 (UAP with delayed planting) to 88.33 days (CCRI with optimum planting). Genotype means over sites and planting dates revealed that improved populations - $\mathrm{C}_{2}(79.00$ days) and $\mathrm{C}_{1}$ (79.42 days) utilized lesser and at par days to silking. However, check genotypes Kiramat and Jalal consumed the highest and same number of days to silking with 86.33 and 84.58 days, respectively. diferencias altamente significativas para los días hasta el ensilado y la longitud de la planta, mientras que no fueron significativas para la altura de la mazorca y el rendimiento del grano. Los genotipos revelaron una mayor variabilidad genética entre los lugares y las fechas de siembra, las cuales pueden ser utilizadas para identificar y mejorar las poblaciones cíclicas de maíz. Se registraron variaciones significativas entre las poblaciones seleccionadas de maíz $\mathrm{S}_{1}$ para la longitud de la planta, mazorcas por planta, hileras de grano por mazorca, peso de mil granos y rendimiento de grano (Sohail et al., 2018; Sheikh et

Table 2. Mean squares and significance test for traits evaluated at two sites with different planting dates.

Cuadro 2. Cuadrados medios y prueba de significancia para los rasgos evaluados en dos lugares con diferentes fechas de siembra.

\begin{tabular}{ccccccc}
\hline $\begin{array}{c}\text { Sources of } \\
\text { variation }\end{array}$ & d.f. & $\begin{array}{c}\text { Days to } \\
\text { silking }\end{array}$ & $\begin{array}{c}\text { Cob } \\
\text { height }\end{array}$ & $\begin{array}{c}\text { Cobs } \\
\text { plant }\end{array}$ & $\begin{array}{c}\text { Cob } \\
\text { length }\end{array}$ & $\begin{array}{c}\text { Grain } \\
\text { yield }\end{array}$ \\
\hline Sites (L) & 1 & $32.00^{\mathrm{NS}}$ & $2862.72^{*}$ & $0.026^{\mathrm{NS}}$ & $0.02^{\mathrm{NS}}$ & $15,297.98^{\mathrm{NS}}$ \\
Error & 4 & 6.61 & 34.51 & 0.009 & 0.51 & $1,761,132.26$ \\
Planting dates (P) & 1 & $2312.00^{* *}$ & $1942.72^{*}$ & $0.005^{\mathrm{NS}}$ & $4.37^{\mathrm{NS}}$ & $63,884,859.23^{*}$ \\
$\mathrm{~L} \times \mathrm{P}$ & 1 & $16.06^{\mathrm{NS}}$ & $522.72^{\mathrm{NS}}$ & $0.003^{\mathrm{NS}}$ & $1.16^{\mathrm{NS}}$ & $1,610,509.67^{\mathrm{NS}}$ \\
Error & 4 & 7.69 & 156.60 & 0.024 & 1.46 & $3,014,741.17$ \\
Genotypes (G) & 5 & $103.82^{* *}$ & $312.22^{*}$ & $0.005^{\mathrm{NS}}$ & $10.84^{* *}$ & $2,812,111.65^{*}$ \\
$\mathrm{G} \times \mathrm{L}$ & 5 & $12.70^{\mathrm{NS}}$ & $43.89^{\mathrm{NS}}$ & $0.006^{\mathrm{NS}}$ & $4.31^{* *}$ & $1,019,174.16^{\mathrm{NS}}$ \\
G $\times \mathrm{P}$ & 5 & $7.43^{\mathrm{NS}}$ & $81.69^{\mathrm{NS}}$ & $0.002^{\mathrm{NS}}$ & $0.19^{\mathrm{NS}}$ & $522,067.62^{\mathrm{NS}}$ \\
G $\times \mathrm{L} \times \mathrm{P}$ & 5 & $6.56^{\mathrm{NS}}$ & $116.56^{\mathrm{NS}}$ & $0.004^{\mathrm{NS}}$ & $0.86^{\mathrm{NS}}$ & $754,191.87^{\mathrm{NS}}$ \\
\hline Error & 40 & 6.65 & 90.74 & 0.006 & 0.56 & $834,439.78$ \\
\hline CV $(\%)$ & - & 3.13 & 13.14 & 7.99 & 4.24 & 18.36 \\
\hline
\end{tabular}

$* *$, *: Significant at $\mathrm{p} \leq 0.01$ and $\mathrm{p} \leq 0.05$, respectively, NS: Non-significant.

$* *$, *: Significativo a $\mathrm{p} \leq 0,01$ y $\mathrm{p} \leq 0,05$, respectivamente, NS: No significativo.

In genotype by site by planting date interactions $(\mathrm{G} \times \mathrm{L} \times \mathrm{P})$, the mean days to silking varied from $73.33\left(\mathrm{C}_{2}\right.$ with delayed planting at UAP) to 92.67 days (Kiramat with al., 2019). La interacción genotipo $\mathrm{x}$ ambiente reveló variaciones significativas para las variables de floración y rendimiento, las cuales autenticaron que las poblaciones 
Rev. Fac. Agron. (LUZ). 2021, 38(3): 608-630. Julio-Septiembre.

Sajjad et al.

ISSN 2477-9407

optimum planting at CCRI) (table 3). The improved population - $\mathrm{C}_{2}$ with delayed planting at UAP $(73.33$ days) and CCRI (73.67 days), check genotype Jalal with delayed planting at UAP (73.67 days), population - $\mathrm{C}_{1}$ with delayed planting at CCRI (74.67 days) and UAP (75.33 days) revealed the lesser and same number of days to silking. Check varieties Kiramat and Jalal with optimum planting at both sites owned maximum and same days to silking ranged between 90.00 to 92.67 days, respectively. Overall, the improved populations - $\mathrm{C}_{2}$ and $\mathrm{C}_{1}$ showed early silking as compared to check genotypes across the environments. Genotypes with delayed planting utilized less days to silking at UAP than CCRI across the environments which might be due to abiotic stress conditions i.e., temperature and initiation of reproductive phase.

Present findings authenticated that newly developed superior populations were relatively more steady and sustainable. Based upon the pessimistic responses, a desirable decline in days flowering was recorded in maize selected $\mathrm{S}_{1}$ populations (Guimaraes et al., 2018; Sajjad et $a l ., 2020 \mathrm{a}, \mathrm{d})$. Due to repeated selfpollination and intensive selection, the affirmative genes could have been assembled, which made stable the maize $\mathrm{C}_{1}$ and $\mathrm{C}_{2}$ populations and enunciated steadiness in early maturity (Sajjad et al., 2020b, c).

\section{Cob height}

Overall, the maize genotypes exhibited lower mean values for cob height at CCRI $(66.17 \mathrm{~cm})$ than UAP (table 3). For de maíz no podían mantener un comportamiento fenotípico uniforme en diversos entornos (Sajjad et al., 2020a, b). La interacción genotipo $\mathrm{x}$ lugar revelaron diferencias significativas $(p \leq 0,05)$ para la longitud de mazorca, mientras que no fueron significativas para los otros rasgos. Sin embargo, las interacciones lugar $x$ fecha de siembra, genotipo $x$ fecha de siembra $\mathrm{y}$ genotipo $\mathrm{x}$ sitio $\mathrm{x}$ fecha de siembra revelaron diferencias no significativas para todos los rasgos. Estudios anteriores revelaron que la interacción $\mathrm{G} \times \mathrm{E}$ no fue significativa para los rasgos de precocidad, la altura de la planta y de la mazorca, los rasgos de la mazorca y el peso de 1000 granos en el maíz (Annor et al., 2019).

\section{Días para el ensilado}

En cuanto a los lugares, las poblaciones de maíz consumieron menos días hasta el ensilado en UAP (81,81 días) en comparación al CCRI (83,14 días), podría deberse a las elevadas temperaturas de la UAP, que dieron lugar a condiciones de estrés y a una floración temprana (cuadro 3 y Figura 1). En cuanto a los tiempos de siembra, los genotipos con siembra tardía mostraron menos días al ensilado (76,81 días) que la siembra óptima (88,14 días). En promedio, la siembra tardía toma menos días al ensilado (75,67 y 77,94 días) que la siembra óptima (87,94 y 88,33 días) con un descenso de 11,33 días (12.85 \%). Para las interacciones de lugares por fechas de siembra $(\mathrm{L} \times \mathrm{P})$, el tiempo a ensilado varió de 75,67 (UAP con siembra tardía) a 88,33 días (CCRI con siembra óptima). Las medias de los genotipos en función de los lugares 
planting dates, the least cob height was recorded with delayed planting $(67.28 \mathrm{~cm})$ by comparing to optimum planting $(77.67$ $\mathrm{cm})$, with a decrease of $10.39 \mathrm{~cm}(13.38 \%)$. For site $\times$ planting date, delayed sown populations exhibited least cob height $(58.28 \mathrm{~cm})$ while other relationships of sites and planting dates observed with the highest cob height varied from 74.06 to $81.28 \mathrm{~cm}$. Populations means over sites and planting dates were between 67.50 $\left(\mathrm{C}_{0}\right)$ to $81.67 \mathrm{~cm}$ (Jalal) for cob height. Five genotypes $\left(\mathrm{C}_{0}, \mathrm{C}_{1}, \mathrm{C}_{2}\right.$, Azam, and Kiramat) exhibited least and same cob height varied between 67.50 to $72.67 \mathrm{~cm}$ while check cultivar Jalal attained the highest cob height $(81.67 \mathrm{~cm})$.

In genotype $\times$ site $\times$ planting date interactions, the mean vales varied from 52.33 (Azam at CCRI with delayed planting) to $93.33 \mathrm{~cm}$ (Jalal at CCRI with optimum planting) (table 3). However, the least and alike cob height was obtained in check cultivars i.e., Azam (52.33), and Kiramat $(60.00 \mathrm{~cm})$, and improved populations $\mathrm{C}_{2}(57.33 \mathrm{~cm})$ and $\mathrm{C}_{1}(61.67 \mathrm{~cm})$ when were planted late at CCRI. In the case of morphological traits such as cob height, the cyclical populations $\left(\mathrm{C}_{0}, \mathrm{C}_{1}\right.$, and $\left.\mathrm{C}_{2}\right)$ presented least and identical values, while check variety Jalal presumed the highest cob height.

Significant decline and enhancement were recorded for plant stature, cob height, and yield traits, respectively with the selection in maize $\mathrm{S}_{1}$ progenies (Kolawole et al., 2017). Similarly, considerable genetic variation for plant stature and cob height have also been reported among maize populations (Ayiga-Aluba et al., 2015; Khamkoh et al., 2019). y las fechas de siembras revelaron que las poblaciones mejoradas -C2 (79,00 días) y $\mathrm{C} 1$ (79,42 días) utilizaron menos e iguales días hasta el ensilado. Sin embargo, los genotipos de control Kiramat y Jalal consumieron el mayor y mismo número de días hasta el ensilado con 86,33 y 84,58 días, respectivamente.

Las interacciones de genotipo por lugar por día de siembra $(\mathrm{G} \times$ $\mathrm{L} \times \mathrm{P}$ ), en los días medios hasta el ensilado, variaron de $73,33\left(\mathrm{C}_{2}\right.$ con siembra tardía en el UAP) a 92,67 días (Kiramat con una siembra óptima en el CCRI) (cuadro 3). La población mejorada - $\mathrm{C}_{2}$ con siembra tardía en UAP (73,33 días) y CCRI (73,67 días), el genotipo control Jalal con siembra tardía en UAP (73,67 días), población - $\mathrm{C}_{1}$ con siembra tardía en CCRI (74,67 días) y en UAP (75,33 días) revelaron los menores y similares números de días hasta el ensilado. Las variedades control Kiramat y Jalal con una siembra óptima en ambos lugares poseían el máximo y el mismo rango de días hasta el ensilado, entre 90,00 a 92,67 días, respectivamente. En general, las poblaciones mejoradas - $\mathrm{C}_{2}$ y $\mathrm{C}_{1}$ mostraron un ensilado temprano en comparación a los genotipos control en los entornos. Los genotipos con siembra tardía utilizaron menos días hasta el ensilado en UAP que CCRI entre los ambientes, lo cual puede producirse debido a las condiciones de estrés abiótico, tales como temperatura e iniciación de la fase reproductiva.

Los presentes hallazgos demostraron que las poblaciones superiores desarrolladas, fueron relativamente más constantes y 
Rev. Fac. Agron. (LUZ). 2021, 38(3): 608-630. Julio-Septiembre.

Sajjad et al.

ISSN 2477-9407

Table 3. Mean performance of maize populations and check genotypes over sites and planting dates for days to silking and cob height.

Cuadro 3. Rendimiento medio de las poblaciones de maíz y de los genotipos de control sobre los lugares y las fechas de siembra para los días hasta el ensilado y la altura de la mazorca.

\begin{tabular}{|c|c|c|c|c|c|}
\hline \multirow[b]{2}{*}{ Genotypes } & \multicolumn{2}{|c|}{ CCRI } & \multicolumn{2}{|c|}{ UAP } & \multirow{3}{*}{$\begin{array}{l}\text { Means } \\
\text { (days) }\end{array}$} \\
\hline & $\begin{array}{c}\text { Early } \\
\text { planting }\end{array}$ & $\begin{array}{c}\text { Late } \\
\text { planting }\end{array}$ & $\begin{array}{c}\text { Early } \\
\text { planting }\end{array}$ & $\begin{array}{c}\text { Late } \\
\text { planting }\end{array}$ & \\
\hline Cyclical populations & \multicolumn{4}{|c|}{ Days to silking (days) } & \\
\hline PSEV3- $\mathrm{C}_{0}$ & 89.33 & 78.00 & 90.33 & 77.67 & 83.83 \\
\hline PSEV3- $\left(\mathrm{S}_{1}\right)-\mathrm{C}_{1}$ & 84.00 & 74.67 & 83.67 & 75.33 & 79.42 \\
\hline PSEV3- $\left(\mathrm{S}_{2}\right)-\mathrm{C}_{2}$ & 84.00 & 73.67 & 85.00 & 73.33 & 79.00 \\
\hline \multicolumn{6}{|l|}{ Check genotypes (G) } \\
\hline Azam & 88.00 & 77.00 & 86.00 & 75.67 & 81.67 \\
\hline Jalal & 92.00 & 82.00 & 90.67 & 73.67 & 84.58 \\
\hline Kiramat & 92.67 & 82.33 & 92.00 & 78.33 & 86.33 \\
\hline Means (days) & 88.33 & 77.94 & 87.94 & 75.67 & - \\
\hline Means (sites - L) & 83.14 & - & 81.81 & - & - \\
\hline Means (planting times - $\mathrm{P}$ ) & 88.14 & - & - & 76.81 & - \\
\hline \multicolumn{6}{|c|}{$\mathrm{LSD}_{0.05}$ Genotypes: 2.13 , Sites: 1.68 , Planting times: $1.82, \mathrm{G} \times \mathrm{P}: \mathrm{NS}, \mathrm{G} \times \mathrm{L}: \mathrm{NS}, \mathrm{L} \times \mathrm{P}: \mathrm{NS}, \mathrm{G} \times \mathrm{P} \times \mathrm{L}: \mathrm{NS}$} \\
\hline Cyclical populations & \multicolumn{4}{|c|}{ Cob height (cm) } & $\begin{array}{c}\text { Means } \\
(\mathrm{cm})\end{array}$ \\
\hline PSEV3- $\mathrm{C}_{0}$ & 66.67 & 54.33 & 81.33 & 67.67 & 67.50 \\
\hline PSEV3- $\left(\mathrm{S}_{1}\right)-\mathrm{C}_{1}$ & 63.33 & 61.67 & 73.33 & 73.33 & 67.92 \\
\hline PSEV3- $\left(\mathrm{S}_{2}\right)-\mathrm{C}_{2}$ & 71.00 & 57.33 & 85.00 & 77.33 & 72.67 \\
\hline \multicolumn{6}{|l|}{ Check genotypes $(\mathrm{G})$} \\
\hline Azam & 77.67 & 52.33 & 79.00 & 80.67 & 72.42 \\
\hline Jalal & 93.33 & 64.00 & 86.33 & 83.00 & 81.67 \\
\hline Kiramat & 72.33 & 60.00 & 82.67 & 75.67 & 72.67 \\
\hline Means (cm) & 74.06 & 58.28 & 81.28 & 76.28 & - \\
\hline Means (sites - L) & 66.17 & - & 78.78 & - & - \\
\hline Means (planting times - P) & 77.67 & - & - & 67.28 & - \\
\hline \multicolumn{6}{|c|}{ LSD $_{0.05}$ Genotypes: 7.86, Sites: 8.19, Planting times: 3.85, G $\times$ P: NS, G $\times$ L: NS, L $\times$ P: NS, G $\times$ P $\times$ L : NS } \\
\hline Cyclical populations & \multicolumn{4}{|c|}{ Cobs plant $^{-1}(\#)$} & $\begin{array}{c}\text { Means } \\
(\#)\end{array}$ \\
\hline PSEV3- $\mathrm{C}_{0}$ & 0.98 & 0.87 & 0.95 & 0.96 & 0.94 \\
\hline PSEV3-( $\left.\mathrm{S}_{1}\right)-\mathrm{C}_{1}$ & 0.99 & 1.03 & 0.99 & 0.93 & 0.99 \\
\hline $\begin{array}{c}\text { PSEV3- }\left(\mathrm{S}_{2}\right)-\mathrm{C}_{2} \\
\text { Check genotypes }(\mathrm{G})\end{array}$ & 0.94 & 0.90 & 0.99 & 1.00 & 0.96 \\
\hline Azam & 0.93 & 0.90 & 0.94 & 0.97 & 0.93 \\
\hline Jalal & 0.92 & 0.88 & 0.97 & 0.95 & 0.93 \\
\hline Kiramat & 0.90 & 0.91 & 0.96 & 0.99 & 0.94 \\
\hline Means (\#) & 0.94 & 0.91 & 0.97 & 0.97 & - \\
\hline Means (sites - L) & 0.93 & - & 0.97 & - & - \\
\hline Means (planting times - P) & 0.96 & - & - & 0.94 & - \\
\hline
\end{tabular}

LSD $_{0.05}$ Genotypes: NS, Sites: NS, Planting times: NS, G $\times$ P: NS, G $\times$ L: NS, L $\times$ P: NS, G $\times$ P $\times$ L: NS 
Rev. Fac. Agron. (LUZ). 2021, 38(3): 608-630. Julio-Septiembre.

Sajjad et al.

ISSN 2477-9407

\section{Cobs per plant}

On average, the maximum prolificacy was recorded at UAP (0.97), pursued by CCRI (0.93) (table 3). For planting dates, the maximum cobs per plant were obtained by the genotypes with optimum planting (0.96), followed by delayed planting (0.94) with a decline of $0.02(2.08$ $\%)$. The site by planting date means varied between 0.91 (CCRI with delayed planting) to 0.97 (UAP with optimum and delayed planting). Genotype means over sites enunciated that improved populations - $\mathrm{C}_{1}(0.99)$ and $\mathrm{C}_{2} \quad(0.96)$ revealed maximum number of cobs per plant, followed by origional population - $\mathrm{C}_{0}(0.94)$ while least and same cobs per plant (0.93) were observed in check genotypes Azam and Jalal (table 4).

In $\mathrm{G} \times \mathrm{L} \times \mathrm{P}$ interactions, improved populations - $\mathrm{C}_{1}$ and $\mathrm{C}_{2}$ with delayed planting revealed maximum cobs per plant at CCRI (1.03) and UAP (1.00), respectively. However, the minimum number of cobs per plant were observed in origional population - $\mathrm{C}_{0}$ (0.87) and check cultivar Jalal (0.88) with delayed planting at CCRI.

\section{Cob length}

For sites, the cob length values over genotypes were $17.57 \mathrm{~cm}$ and $17.72 \mathrm{~cm}$ at CCRI and UAP, respectively (table 4). In planting dates, the cob length in the genotypes ranged between 17.43 (delayed planting) to $17.86 \mathrm{~cm}$ (optimum planting), respectively with a decline of $0.43 \mathrm{~cm}(2.47 \%)$. For site by planting date, the genotype means varied between 17.24 (CCRI with delayed planting) to $17.90 \mathrm{~cm}$ (CCRI with optimum planting). sostenibles. En comparación con algunos resultados no satisfactorios, se registró una disminución deseable de los días a floración en las poblaciones S1 de maíz seleccionadas (Guimaraes et al., 2018; Sajjad et al., 2020a, d). Debido a la autopolinización repetida y a la selección intensiva, los genes deseables pudieron haber sido fijados, los cuales hicieron estables las poblaciones de maíz $\mathrm{C}_{1}$ y $\mathrm{C}_{2} \mathrm{y}$ determinaron la estabilidad en la madurez temprana (Sajjad et al., $2020 \mathrm{~b}, \mathrm{c})$.

\section{Altura de la mazorca}

En general, los genotipos del maíz mostraron valores medios menores para la altura de la mazorca en CCRI $(66,17 \mathrm{~cm}$ ) que en UAP (cuadro 3). Para las fechas de siembra, la menor altura fue registrada para la siembra tardía $(67,28 \mathrm{~cm})$ en comparación con la siembra óptima $(77,67 \mathrm{~cm})$, con un descenso de 10,39 cm (13,38\%). Para lugar por fecha de siembra, las poblaciones de siembra tardía mostraron una menor altura $(58,28$ $\mathrm{cm}$ ), mientras en otras interacciones de lugares por fechas de siembra se observó que la altura más alta de mazorca varió de 74,06 a $81,28 \mathrm{~cm}$. Las medias de las poblaciones sobre los lugares y las fechas de siembra fueron entre $67,50\left(\mathrm{C}_{0}\right)$ a $81,67 \mathrm{~cm}$ (Jalal) para la altura de mazorca. Cinco genotipos $\left(\mathrm{C}_{0}, \mathrm{C}_{1}, \mathrm{C}_{2}\right.$, Azam, y Kiramat) mostraron la menor y misma altura, que varió entre 67,50 a $72,67 \mathrm{~cm}$, mientras que el cultivo control Jalal alcanzó la mayor altura $(81,67 \mathrm{~cm})$.

En las interacciones de genotipo $\mathrm{x}$ lugar $\mathrm{x}$ fecha de siembra, los valores 
Rev. Fac. Agron. (LUZ). 2021, 38(3): 608-630. Julio-Septiembre.

Sajjad et al.

ISSN 2477-9407

Table 4. Mean performance of maize populations and check genotypes over sites and planting dates for cob length and grain yield.

Cuadro 4. Rendimiento medio de las poblaciones de maíz y de los genotipos control sobre los lugares y las fechas de siembra para la longitud de la mazorca y el rendimiento de grano.

\begin{tabular}{|c|c|c|c|c|c|}
\hline \multirow{2}{*}{ Genotypes } & \multicolumn{2}{|c|}{ CCRI } & \multicolumn{2}{|c|}{ UAP } & \\
\hline & $\begin{array}{c}\text { Early } \\
\text { planting }\end{array}$ & $\begin{array}{c}\text { Late } \\
\text { planting }\end{array}$ & $\begin{array}{c}\text { Early } \\
\text { planting }\end{array}$ & $\begin{array}{c}\text { Late } \\
\text { planting }\end{array}$ & \\
\hline Cyclical populations & \multicolumn{4}{|c|}{ Cob length $(\mathrm{cm})$} & Means (cm) \\
\hline PSEV3- $\mathrm{C}_{0}$ & 15.63 & 14.79 & 16.67 & 16.8 & 15.97 \\
\hline PSEV3- $\left(\mathrm{S}_{1}\right)-\mathrm{C}_{1}$ & 17.38 & 16.91 & 17.95 & 17.46 & 17.43 \\
\hline PSEV3-( $\left.\mathrm{S}_{2}\right)-\mathrm{C}_{2}$ & 18.9 & 18.38 & 17.78 & 18.17 & 18.31 \\
\hline Check genotypes (G) & & & & & \\
\hline Azam & 17.56 & 16.05 & 17.78 & 18.04 & 17.36 \\
\hline Jalal & 18.8 & 18.5 & 18.56 & 18.07 & 18.48 \\
\hline Kiramat & 19.13 & 18.8 & 18.15 & 17.15 & 18.31 \\
\hline Means (cm) & 17.90 & 17.24 & 17.82 & 17.62 & \\
\hline Means (sites - L) & 17.57 & - & 17.72 & - & \\
\hline Means (planting times - P) & 17.86 & - & - & 17.43 & \\
\hline
\end{tabular}

$\mathrm{LSD}_{0.05}$ Genotypes: 0.62 , Sites: NS, Planting times: NS, G $\times \mathrm{P}: \mathrm{NS}, \mathrm{G} \times \mathrm{L}: 0.59, \mathrm{~L} \times \mathrm{P}: \mathrm{NS}, \mathrm{G} \times \mathrm{P} \times \mathrm{L}=\mathrm{NS}$

\begin{tabular}{|c|c|c|c|c|c|}
\hline \multirow{2}{*}{$\frac{\text { Cyclical populations }}{{\text { PSEV } 3-\mathrm{C}_{0}}}$} & \multicolumn{4}{|c|}{ Grains yield (kg ha $\left.{ }^{-1}\right)$} & \multirow{2}{*}{$\frac{\text { Means }\left(\mathbf{k g ~ h a} \mathbf{~}^{-1}\right)}{4298}$} \\
\hline & 4846 & 3137 & 5344 & 3866 & \\
\hline PSEV3-( $\left.\mathrm{S}_{1}\right)-\mathrm{C}_{1}$ & 5780 & 3947 & 6042 & 3408 & 4794 \\
\hline PSEV3- $\left(\mathrm{S}_{2}\right)-\mathrm{C}_{2}$ & 6524 & 4082 & 5354 & 4585 & 5136 \\
\hline \multicolumn{6}{|l|}{ Check genotypes (G) } \\
\hline Azam & 5199 & 3460 & 5825 & 4574 & 4765 \\
\hline Jalal & 7793 & 4326 & 6240 & 4623 & 5746 \\
\hline Kiramat & 6165 & 4258 & 5883 & 4122 & 5107 \\
\hline Means $\left(\mathrm{kg} \mathrm{ha}^{-1}\right)$ & 6051 & 3868 & 5781 & 4196 & - \\
\hline Means (sites - L) & 4960 & - & 4989 & - & - \\
\hline Means (planting times - P) & 5916 & - & - & 4032 & - \\
\hline
\end{tabular}

LSD $_{0.05}$ Genotypes: 750.0, Sites: NS, Planting times: 1114.0, G $\times$ P: NS, G $\times$ L: NS, L $\times$ P: NS, G $\times$ P $\times$ L: NS

Genotype means over sites and planting dates revealed that the highest and at par cob length was obtained in maize improved population - $\mathrm{C}_{2}(18.31 \mathrm{~cm})$, and check varieties Jalal $(18.48 \mathrm{~cm})$ and Kiramat $(18.31 \mathrm{~cm})$ (table 4). Nevertheless, the least cob length was recorded in base population - $\mathrm{C}_{0}(15.97 \mathrm{~cm})$. In genotype medios variaron de 52,33 (Azam en CCRI con siembra tardía) a $93,33 \mathrm{~cm}$ (Jalal en CCRI con siembra óptima) (cuadro 3). Sin embargo, la altura de mazorca más baja y parecida se obtuvo en los cultivares de control, es decir, Azam $(52,33)$ y Kiramat $(60,00$ $\mathrm{cm})$, y en las poblaciones mejoradas $\mathrm{C}_{2}(57,33 \mathrm{~cm})$ y $\mathrm{C}_{1}(61,67 \mathrm{~cm})$ cuando 
by site by planting date interactions, the highest cob length was exhibited by improved population - $\mathrm{C}_{2}(18.90$ $\mathrm{cm}$ ), check genotypes Kiramat (19.13 $\mathrm{cm})$ and Jalal $(18.80 \mathrm{~cm})$ with optimum planting at CCRI. However, origional population - $\mathrm{C}_{0}$ with delayed (14.79 $\mathrm{cm})$ and optimum planting (15.63) at CCRI recorded with least cob length.

\section{Grain yield}

For sites, overall the utmost grain yield was obtained in maize populations grown at UAP (4989 kg.ha-1), pursued by CCRI (4960 $\mathrm{kg} \cdot \mathrm{ha}^{-1}$ ) because of the genotypes extra least grain yield at CCRI with delayed planting (3868 kg.ha-1) which affected the average yield (table 4). However, by comparing the average grain yield of the genotypes with optimum planting at both sites, the CCRI (6051 kg.ha-1) was leading than UAP (5781 kg.ha ${ }^{-1}$ ) which might be due to longer growth period caused by low temperature and delayed flowering at CCRI (figure 1). Overall, the populations with optimum planting exposed the enhanced grain yield (5916 kg.ha-1), pursued by delayed planting (4032 kg.ha-1) with decline of $31.85 \%$ (1884 kg.ha-1). Site by planting date relationship displayed that genotypes with optimum planting produced superior grain yield at CCRI (6051 kg.ha-1), which was found at par with UAP (5781 kg.ha-1). Nonetheless, the genotypes with delayed planting at CCRI exhibited least grain yield (3868 kg.ha-1).

Maize populations across environments enunciated that the highest and same grain yield was presented by superior population - se sembraron tarde en el CCRI. En el caso de las poblaciones cíclicas $\left(\mathrm{C}_{0}, \mathrm{C}_{1}\right.$, y $\mathrm{C}_{2}$ ) presentaron menos e idénticos valores, mientras que la variedad de control Jalal presentó la mayor altura de mazorca.

Se registró una disminución y un aumento significativo de la estatura de las plantas y los rasgos de rendimiento, respectivamente con la selección en las progenies de maíz S1 (Kolawole et al., 2017). Del mismo modo, también se ha informado de una considerable variación genética para la estatura de la planta y la altura de la mazorca entre las poblaciones de maíz (AyigaAluba et al., 2015; Khamkoh et al., 2019).

\section{Mazorcas por planta}

En promedio, la mayor prolificidad se registró en UAP $(0,97)$, seguido de CCRI $(0,93)$ (cuadro 3). En cuanto a las fechas de siembra, los máximos de mazorcas por planta se obtuvieron en los genotipos con siembra óptima $(0,96)$, seguidos de las de siembra tardía $(0,94)$ con una disminución de $0,02(2,08 \%)$. Las medias de los lugares por fecha de siembra variaron de 0,91 (CCRI con siembra tardía) a 0,97 (UAP con siembra óptima y tardía). Las medias de los genotipos por lugares determinaron que las poblaciones mejoradas - $\mathrm{C} 1(0,99)$ y $\mathrm{C} 2$ $(0,96)$ revelaron el máximo número de mazorcas por planta, seguidas por la población original - $\mathrm{C}_{0}(0,94)$, mientras que la menor e igual cantidad de mazorcas por planta $(0,93)$ se observó en los genotipos de control Azam y Jalal (cuadro 4).

En las interacciones $\mathrm{G} \times \mathrm{L} \times \mathrm{P}$, las poblaciones mejoradas $-\mathrm{C}_{1} \mathrm{y}$ 
Rev. Fac. Agron. (LUZ). 2021, 38(3): 608-630. Julio-Septiembre.

Sajjad et al.

ISSN 2477-9407

$\mathrm{C}_{2}$ (5136 kg.ha-1) and check varieties Jalal (5746 kg.ha ${ }^{-1}$ ) and Kiramat (5107 kg.ha-1) (table 4). Though, the origional population - $\mathrm{C}_{0}$ exhibited least grain yield $\left(4298 \mathrm{~kg} \cdot \mathrm{ha}^{-1}\right)$. The interactions due to genotype $\times$ site $\times$ planting date exposed that the maximum and alike grain yield was obtained in check variety Jalal (7793 $\left.\mathrm{kg} \cdot \mathrm{ha}^{-1}\right)$ and advanced population $-\mathrm{C}_{2}$ (6524 kg.ha ${ }^{-1}$ ) with optimum planting at CCRI. Nevertheless, the decreased grain yield was recorded in origional population $-\mathrm{C}_{0}$ at CCRI with delayed planting (3137 kg.ha-1).

Results further revealed that above promising improved population - $\mathrm{C}_{2}$ and $\mathrm{C}_{1}$ were best performing for cobs.plant ${ }^{-1}$, cob length and grain yield with optimum planting at CCRI. However, origional population - $\mathrm{C}_{0}$ showed least mean values and unproductive recital for yield related parameters with optimum and delayed plantings at both sites. Past studies also authenticated that improved populations revealed best performance and the highest grain yield than base population, which confirmed that might the feasible genes accumulated in the particular versions of the maize populations (Khamkoh et al., 2019; Kolawole et al., 2019). Significant impact of the recurrent selection cycles was observed on cob traits and grain yield, and the improved populations $\mathrm{C}_{1}$ and $\mathrm{C}_{2}$ executed better performance than maize base population (Ayiga-Aluba et al., 2015; Sohail et al., 2018; Sajjad et al., 2020a, b). For quantitative traits, the recurrent selection efficiently enhanced the occurrence of enviable
$\mathrm{C}_{2}$ con siembra tardía revelaron la máxima cantidad de mazorcas por planta en CCRI $(1,03)$ y en UAP $(1,00)$, respectivamente. Sin embargo, el mínimo número de mazorcas por plantas se observó en poblaciones originales - $\mathrm{C}_{0}(0,87)$ y en el cultivo de control Jalal $(0,88)$ con siembra tardía en CCRI.

\section{Longitud de la mazorca}

Para los lugares, los valores de longitud de la mazorca fueron 17,57 $\mathrm{cm}$ y $17,72 \mathrm{~cm}$ en CCRI y en UAP, respectivamente (cuadro 4). En las fechas de siembra, la longitud de la mazorca en los genotipos osciló entre 17,43 (siembra tardía) a $17,86 \mathrm{~cm}$ (plantación óptima), respectivamente con un descenso de $0,43 \mathrm{~cm}(2,47 \%)$. Para el lugar por fecha de siembra, las medias del genotipo variaron entre 17,24 (CCRI con siembra tardía) a $17,90 \mathrm{~cm}$ (CCRI con siembra óptima).

Las medias de los genotipos en función de los lugares y las fechas de siembra revelaron la longitud de mazorca más alta, y se obtuvo en la población mejorada de maíz - C2 $(18,31 \mathrm{~cm})$, y en las variedades de control Jalal $(18,48 \mathrm{~cm})$ y Kiramat $(18,31 \mathrm{~cm})$ (cuadro 4). Sin embargo, la menor longitud de mazorca se registró en la población base - $\mathrm{C}_{0}(15,97 \mathrm{~cm})$. En las interacciones genotipo por lugar y fecha de siembra, la mayor longitud de mazorca se presentó para la población mejorada - $\mathrm{C}_{2}(18,90 \mathrm{~cm})$, los genotipos de control Kiramat $(19,13 \mathrm{~cm})$ y Jalal $(18,80 \mathrm{~cm})$ con plantación óptima en CCRI. Sin embargo, la población original - $\mathrm{C}_{0}$ con retraso $(14,79 \mathrm{~cm})$ y siembra óptima $(15,63)$ en CCRI registró la menor longitud de mazorca. 
Rev. Fac. Agron. (LUZ). 2021, 38(3): 608-630. Julio-Septiembre.

Sajjad et al.

genes in a maize population and the adverse genes were eventually bared to the early selection (Andorf et al., 2019; Sajjad et al., 2020c, d).

Recurrent selection being an imperative breeding approach, reinstatement of genetic inconsistency, and consequent development within the maize populations can be made through early generations (Sajjad et al., 2016; Sampoux et al., 2020). Though late maturing maize populations are high yielding due to the accretion of relatively greater magnitude of photosynthates; however, early maturity is evenly pleasing to avoid the maize crop from biotic and abiotic apprehensions mostly practised at later growth stages.

\section{Conclusions}

Maize newly developed improved populations PSEV3-( $\left.\mathrm{S}_{1}\right)-\mathrm{C}_{1}$ and PSEV3- $\left(\mathrm{S}_{2}\right)-\mathrm{C}_{2}$ revealed earliness and least mean values for days to silking and cob height. However, these superior populations showed increased mean values for prolificacy, cob length and eventually increased grain yield compared to original population and check genotypes across the environments. Promising populations might accumulated favourable genes resulting in stability for earliness and increased grain yield. Therefore, for improving maize populations, the selfed progeny recurrent selection was found as more efficient.

\section{End of English version}

\section{Rendimiento de grano}

Para los lugares, en general, el mayor rendimiento de grano se obtuvo en las poblaciones de maíz sembradas en UAP (4.989 kg.ha-1), seguidas por CCRI (4.960 kg.ha-1) debido a que los genotipos extra mostraron menos rendimiento de grano en el CCRI con la siembra tardía (3.868 kg.ha-1) lo cual afectó el rendimiento promedio (cuadro 4). Sin embargo, comparando el rendimiento promedio de grano de los genotipos con la siembra óptima en ambos lugares, el CCRI (6.051 kg.ha-1) lideró sobre UAP (5.781 kg.ha ${ }^{-1}$ ), lo cual puede deberse a un periodo de crecimiento más largo causado por la baja temperatura y la floración tardía en CCRI (Figura 1). En general, las poblaciones con siembra óptima expusieron el mayor rendimiento de grano (5.916 kg.ha' ${ }^{-1}$, seguidas por la siembra tardía $\left(4.032 \mathrm{~kg} \cdot \mathrm{ha}^{-1}\right)$ con un descenso del 31,85\% (1.884 $\left.\mathrm{kg} . \mathrm{ha}^{-1}\right)$. La relación lugar por fecha de siembra mostró que los genotipos con plantación óptima produjeron un rendimiento de grano superior en CCRI (6.051 kg.ha-1), lo cual se ubicó a la par con UAP (5.781 kg.ha-1). Sin embargo, los genotipos con plantación tardía en CCRI mostraron el menor rendimiento de grano (3.868 kg.ha-1)

Las poblaciones de maíz en distintos entornos demostraron que el más alto y mismo rendimiento de grano fue obtenido por una población superior $\mathrm{C}_{2}\left(5.136 \mathrm{~kg} \cdot \mathrm{ha}^{-1}\right)$ y las variedades de control Jalal (5.746 kg.ha-1) y Kiramat (5.107 kg.ha-1) (cuadro 4). Aunque la población original - $\mathrm{C}_{0}$ arrojó el menor rendimiento de grano $\left(4.298 \mathrm{~kg} \cdot \mathrm{ha}^{-1}\right)$, las interacciones de genotipo $\times$ lugar $\times$ 
día de siembra demostraron el máximo y mismo rendimiento de grano que se obtuvo con la variedad Jalal (7.793 $\left.\mathrm{kg} \cdot \mathrm{ha}^{-1}\right)$ y la población avanzada $-\mathrm{C}_{2}$ (6.524 kg.ha-1) con siembra óptima en CCRI. Sin embargo, la disminución del rendimiento de grano se registró en la población original - $\mathrm{C}_{0}$ en CCRI con población tardía $\left(3.137 \mathrm{~kg} \cdot \mathrm{ha}^{-1}\right)$.

Los resultados revelaron que las poblaciones mejoradas $\mathrm{C}_{2} \quad \mathrm{y}_{1} \mathrm{C}_{1}$ fueron las más productivas en cuanto a mazorcas.planta ${ }^{-1}$, longitud de mazorca y rendimiento de grano con la plantación óptima en CCRI. Sin embargo, la población original - $\mathrm{C}_{0}$ mostró los valores medios más bajos y un comportamiento improductivo para los parámetros de rendimiento relacionados con las siembras óptimas y tardías en ambos lugares. Estudios anteriores también demostraron que las poblaciones mejoradas revelaron el mejor rendimiento y la mayor producción de grano que la población base, lo que confirmó que los genes deseables pueden ser acumulados en versiones particulares de poblaciones de maíz (Khamkoh et al., 2019; Kolawole et al., 2019). Se observó un impacto significativo de los ciclos de selección recurrente en los rasgos de la mazorca y de rendimiento de grano, y las poblaciones mejoradas $\mathrm{C}_{1} \mathrm{y}_{2}$ demostraron un mejor rendimiento que la población base de maíz (AyigaAluba et al., 2015; Sohail et al., 2018; Sajjad et al., 2020a, b). En el caso de los rasgos cuantitativos, la selección recurrente mejoró eficientemente la aparición de genes deseables en una población de maíz y los genes adversos fueron finalmente despojados de la selección temprana (Andorf et al., 2019; Sajjad et al., 2020c, d).

La selección recurrente es un enfoque de mejoramiento imperativo; el restablecimiento de la inconsistencia genética y el consiguiente desarrollo dentro de las poblaciones de maíz se puede hacer a través de las primeras generaciones (Sajjad et al., 2016; Sampoux et al., 2020). Aunque las poblaciones de maíz de maduración tardía son de alto rendimiento debido a la acumulación de una magnitud relativamente mayor de fotosintatos, la madurez temprana es deseable para evitar que el cultivo de maíz se exponga a amenazas bióticas y abióticas que aparecen en etapas de crecimiento posteriores.

\section{Conclusiones}

Las recientes poblaciones mejoradas de maíz PSEV3- $\left(\mathrm{S}_{1}\right)-\mathrm{C}_{1}$ y PSEV3- $\left(\mathrm{S}_{2}\right)-\mathrm{C}_{2}$ revelaron valores promedios tardíos y menores para los días hasta el ensilado y para la altura de mazorca. Sin embargo, estas poblaciones superiores mostraron un aumento de los valores promedio para prolificidad, la longitud de las mazorcas y finalmente un mayor rendimiento de grano en comparación con la población original y los genotipos de control en todos los entornos. Las poblaciones prometedoras pueden acumular genes favorables que dan lugar a la estabilidad de la precocidad y al aumento del rendimiento de grano. Por lo tanto, para mejorar las poblaciones de maíz, la selección recurrente de la progenie autofecundada resultó ser más eficiente. 


\section{Cited literature}

Ali, S., N.U. Khan, I.H. Khalil, M. Iqbal, S. Gul, S. Ahmed, N. Ali, M. Sajjad, K. Afridi, I. Ali and S.M. Khan. 2017. Environment effects for earliness and grain yield traits in $\mathrm{F}_{1}$ diallel populations of maize (Zea mays L.). J. Sci. Food Agric. 97: 4408-4418.

Ali, S., N.U. Khan, S. Gul, R. Goher, I. Naz, S.A. Khan, N. Ali, M. Saeed, I. Hussain, S.M. Khan and I. Ali. 2019. Heterotic effects for yield related attributes in $\mathrm{F}_{1}$ populations of maize. Pak. J. Bot. 51: 1675-1686.

Ali, S., N.U. Khan, S. Gul, S.U. Khan, I. Tahir, Z. Bibi, I.H. Khalil, N. Ali, S.A. Khan, I. Hussain, I. Ali and S.M. Khan. 2020. Genotype by environment interactions affecting heterotic effects in maize for earliness traits and grain yield. Int. J. Agric. Biol. 23(5): 983-993.

Ali. S., N.U. Khan, R. Gul, I. Naz, R. Goher, N. Ali, S.A. Khan, I. Hussain, M. Saeed and M. Saeed. 2018. Genetic analysis for earliness and yield traits in maize. Pak. J. Bot. 50: 1395-1405.

Andorf, C., W.D. Beavis, M. Huford, S. Smith, W.P. Suza, K. Wang, M. Woodhouse, J. Yu and T. Lübberstedt. 2019. Technological advances in maize breeding: past, present and future. Theor. Appl. Genet. 132(3): 817-849.

Annor, B., B. Badu-Apraku, D. Nyadanu, R. Akromah and M.A.B. Fakorede. 2019. Testcross performance and combining ability of early maturing maize inbreds under multiple-stress environments. Sci. Rep. 9: 13809

Ayiga-Aluba, J., R. Edema, G. Tusiime, G. Asea and P. Gibson. 2015. Response to two cycles of $\mathrm{S}_{1}$ recurrent selection for turcicum leave blight in an open pollinated maize variety population (Longe 5). Adv. Appl. Sci. Res. 6(12): 4-12.

Bricker, B. 1991. Mstat-C: A microcomputer programme for design management and analysis of agronomic research experiments. Michigan State University, East Lansing, Michigan, USA.
Chen, Z.H., Y.F. Zhu, A.G. Wang, X.Y. Guo, X. Wu and P.F. Liu. 2019. Effects of reciprocal recurrent selection on grain yield in two tropical-temperate maize synthetic populations Tuxpeño-Reid and Suwan-Lancaster. Am. J. Plant Sci. 10: 298-308.

Gomez, K.A. and A.A. Gomez. 1984. Statistical Procedures for Agricultural Research. John Wiley and Sons, New York, U. S. A.

Guimaraes, A.G., A.T.A. Junior, J.E.A. Filho, G.F. Pena, C. Vittorazzi and M.G. Pereira. 2018. Population structure and impact of recurrent selection on popcorn using EST-SSR markers. Acta Scient. Agron. 40: e35218: 1-10.

Khamkoh, W., D. Ketthaisong, K. Lomthaisong, K. Lertrat and B. Suriharn. 2019. Recurrent selection method for improvement of lutein and zeaxanthin in orange waxy corn populations. Aust. J. Crop Sci. 13(04): 566-573.

Khan, K., N.U. Khan, M. Iqbal, H. Sher, S. Gul and N. Ali. 2018. Populations of exotic $\times$ locally adapted germplasm A potential source of inbred lines for superior indigenous maize hybrids. Tarim. Bilim. Derg. - J. Agric. Sci. 24: 413-421.

Kolawole, A.O., A. Menkir, E. Blay, K. Ofori and J.G. Kling. 2019. Changes in heterosis of maize (Zea mays L.) varietal cross hybrids after four cycles of reciprocal recurrent selection. Cereal Res. Commun. 47(1): 145-156.

Kolawole, A.O., A. Menkir, M. Gedil, E. Blay, K. Ofori and J.G. Kling. 2017. Genetic divergence in two tropical maize composites after four cycles of reciprocal recurrent selection. Plant Breed. 136(1): 41-49.

Martin, J.H., R.P. Waldren and D.L. Stamp. 2006. Principles of field crop production. $4^{\text {th }}$ edition. Pearson Education, Inc. New Jersey, USA.

Pakistan Economic Survey. 2018-19. Ministry of Finance, Revenue and Economic Affairs, Islamabad, Pakistan. Available in: http://www. finance.gov.pk/survey_1819. html. 
Rev. Fac. Agron. (LUZ). 2021, 38(3): 608-630. Julio-Septiembre.

Sajjad et al.

ISSN 2477-9407

Sajjad, M., N.U. Khan, H. Rahman, K. Khan and G. Hassan. 2016. Response of a maize composite to selfed progeny recurrent selection for earliness and yield traits. Maydica 61(3): 1-8.

Sajjad, M., N.U. Khan, S. Gul, S.U. Khan, I.H. Khalil, S.A. Khan, S. Ali, N. Ali, I. Tahir, Z. Bibi, S.M. Khan and I. Hussain. 2020a. Maize cyclical populations (PSEV3- $\mathrm{C}_{0}, \mathrm{C}_{1}$ and $\mathrm{C}_{2}$ ) response over diverse environments. Int. J. Agric. Biol. 24: 16551664.

Sajjad, M., N.U. Khan, S. Gul, S.U. Khan, I. Tahir, Z. Bibi, S. Ali, N. Ali, S.A. Khan, S.M. Khan and I. Hussain. 2020b. Maize (Zea mays L.) cyclical populations response over environments - developed via recurrent selection. Maydica 65(1): 1-10.

Sajjad, M., N.U. Khan, S. Gul, S.U. Khan, S. Ali, S.A. Khan, N. Ali, I. Tahir, Z. Bibi, I. Hussain and S.M. Khan. 2020c. Assessment of maize $\mathrm{S}_{1}$ and $\mathrm{S}_{2}$ lines for earliness and yield traits developed from base population PSEV3-S ${ }_{0}$ using recurrent selection. Int. J. Agric. Biol. 24: 1806-1814.

Sajjad, M., N.U. Khan, S. Gul, S.U. Khan, Z. Bibi, S. Ali, N. Ali and S.A. Khan. 2020d. Maize improvement through selfed progeny recurrent selection across different environments. Pak. J. Bot. 52(2): 541-549.
Sampoux, J.P., H. Giraud and I. Litrico. 2020. Which recurrent selection scheme to improve mixtures of crop species? Theoretical expectations. G3: Genes, Genomes, Genet. 10(1): 89-107.

Sheikh, F., A. Sohail, T. Burni, F. Hadi, M. Asad, A. Aziz, A. Haleem, M. Maryam and Z. Rahman. 2019. Impact of halfsib family recurrent selection on grain yield in maize population ZM-309. Pure Appl. Biol. 8(3): 2399-2408.

Sohail, A., Q. Hussain, S. Ali, Manzoor, F. Hadi, S. Uddin, F. Bashir, M. Asad, S. Sami and Z. Yousafzai. 2018. Evidence of improving yield and yield attributes via half-sib family recurrent selection in maize (Zea mays L.). Int. J. Curr. Res. Biosci. Plant Biol. 5(12): 45-56.

Udo, E.F., S.O. Ajala and A.B. Olaniyan. 2017. Physiological and morphological changes associated with recurrent selection for low nitrogen tolerance in maize. Euphytica 213: 140. 